\title{
MicroRNA expression levels as diagnostic biomarkers for intraductal papillary mucinous neoplasm
}

\author{
Lei Wang ${ }^{1, *}$, Jianming Zheng ${ }^{2, *}$, Chang Sun ${ }^{1, *}$, Li Wang ${ }^{3}$, Gang Jin ${ }^{4}$, Lei Xin ${ }^{1}$, \\ Zhendong Jin ${ }^{1}$, Dong Wang ${ }^{1}$ and Zhaoshen $\mathrm{Li}^{1}$ \\ ${ }^{1}$ Department of Gastroenterology, Changhai Hospital, Second Military Medical University, Shanghai 200433, China \\ ${ }^{2}$ Department of Pathology, Changhai Hospital, Second Military Medical University, Shanghai 200433, China \\ ${ }^{3}$ Department of Radiology, Changhai Hospital, Second Military Medical University, Shanghai 200433, China \\ ${ }^{4}$ Department of General Surgery, Changhai Hospital, Second Military Medical University, Shanghai 200433, China \\ *These authors have contributed equally to this study \\ Correspondence to: Zhaoshen Li, email: Zhaoshenli.smmu.edu@hotmail.com
}

Keywords: intraductal papillary mucinous neoplasms (IPMNs), miRNA, cancer diagnosis

Received: January 23, $2017 \quad$ Accepted: March 10, $2017 \quad$ Published: May 08, 2017

Copyright: Wang et al. This is an open-access article distributed under the terms of the Creative Commons Attribution License 3.0 (CC BY 3.0), which permits unrestricted use, distribution, and reproduction in any medium, provided the original author and source are credited.

\section{ABSTRACT}

Intraductal papillary mucinous neoplasms (IPMNs) are deadly exocrine mucinous tumors. Currently the molecular features and diagnostic markers of IPMNs are not well understood. In this study, we performed microRNA (miRNA) profiling assays to study the potential roles of miRNAs in IPMNs using 78 cases of IPMN patients and controls. When comparing the miRNA expression between IPMN patient samples and controls, we found that miR-210, miR-223, miR-221, miR-155 and miR-187 were differentially expressed in normal pancreas and IPMNs. We further studied the miRNA expression profiles in different pancreatic diseases and identified miRNA features that are associated with Chronic pancreatitis (CP), IPMN, and Pancreatic ductal adenocarcinoma (PDAC). Therefore, these miRNAs might serve as new risk biomarkers of IPMN and could be useful for future targeted therapies.

\section{INTRODUCTION}

Intraductal papillary mucinous neoplasms (IPMNs) are a class of visceral exocrine mucinous tumors, ranging from benign adenoma to infiltrative carcinoma [1]. IPMNs can be divided into benign (adenoma), borderline, malignant noninvasive (carcinoma in situ) and invasive carcinoma (IC-IPMC, infiltrating duct papillary mucinous carcinoma), depending on whether the infiltrating basement membrane and different cell morphology and histological structure [2]. The IC-IPMC is a very deadly cancer, the 3, 5, 10-year survival rate of IC-IPMC patient is $51 \%, 38 \%$ and $0 \%$, respectively $[3,4]$. Therefore, development of novel, effective diagnostic markers and therapeutic targets for IPMNs is in urgent need for the better treatment of IPMN patients.

MicroRNAs (miRNAs) are small, non-coding RNA molecules participating in post-transcriptional gene regulation and have been identified to be involved in cancer development [5-9]. MiRNAs are frequently mis-regulated in cancers: some miRNAs are lowly expressed in tumor tissues and function as tumor suppressors. On the other hand, some miRNAs are highly expressed in tumor tissues and play the roles as oncogenes to promote oncogenesis [7-10]. Because of their stable nature and the circulating features, miRNAs have been widely used for cancer diagnostics and treatments [11-14]. Importantly, alterations in miRNAs expression have been related to cancer pathogenesis in IPMNs $[15,16]$. Here we studied the differential miRNA expression between benign and malignant IPMN patients and have identified several miRNAs that could serve as novel diagnostic markers for malignant IPMNs.

\section{RESULTS}

Clinicopathologic features of the IPMN patient samples

We first determined the clinicopathologic features of the IPMN patient samples using the well known biochemical 
Table 1: Clinicopathologic features of the IPMN patient samples

\begin{tabular}{|c|c|c|c|c|c|c|c|}
\hline \multirow{2}{*}{ Index } & \multicolumn{3}{|c|}{ Benign } & \multicolumn{3}{|c|}{ Malignant } & \multirow{2}{*}{ p-value } \\
\hline & Case no & Mean & SD & Case no & & SD & \\
\hline Tbil & 38 & 13.412 & 15.129 & 40 & 35.053 & 62.485 & 0.039 \\
\hline DBil & 38 & 6.202 & 11.557 & 40 & 19.610 & 41.526 & 0.056 \\
\hline ALB & 38 & 39.740 & 3.922 & 40 & 39.547 & 4.173 & 0.834 \\
\hline ALT & 38 & 40.607 & 54.439 & 39 & 59.324 & 81.164 & 0.240 \\
\hline AST & 38 & 31.685 & 19.672 & 39 & 49.732 & 54.694 & 0.059 \\
\hline $\mathbf{A K P}$ & 38 & 98.549 & 145.348 & 39 & 174.979 & 204.390 & 0.062 \\
\hline GGT & 37 & 93.240 & 312.035 & 39 & 207.966 & 377.085 & 0.152 \\
\hline GLU & 37 & 5.390 & 1.852 & 39 & 5.176 & 1.122 & 0.545 \\
\hline TG & 10 & 2.518 & 1.789 & 12 & 31.220 & 99.474 & 0.374 \\
\hline $\mathbf{C H}$ & 10 & 2.536 & 0.981 & 12 & 3.376 & 1.370 & 0.121 \\
\hline AMY & 20 & 133.475 & 193.409 & 12 & 61.800 & 69.425 & 0.128 \\
\hline CEA & 33 & 2.222 & 1.219 & 12 & 30.470 & 99.770 & 0.094 \\
\hline CA19-9 & 34 & 22.847 & 38.078 & 12 & 141.576 & 244.062 & 0.008 \\
\hline
\end{tabular}

indicators and tumor markers (Table 1). Comparing the levels of the above indicators, we found that only total bilirubin (T-Bil) and CA19-9 levels are significantly different between the benign and malignant IPMN patient samples, indicating the possible roles of these two factors in the pathogenesis of IPMNs. Indeed, Serum CA19-9 level can be used as a non-invasive preoperative tool to distinguish invasive and benign IPMNs [17], which is consistent with our result. For all other indicators or tumor markers examined in our study, where were no significant difference in their levels between benign and malignant IPMN patient samples, which suggests that the current well known indicators or tumor markers are not effective for the diagnostics of IPMNs.

\section{MiRNA expression profiles in IPMN patient samples}

We next investigated whether miRNAs could serve as diagnostic markers for the IPMNs. First we performed a miRNA profiling study to detect the expression of 15 pancreas related miRNAs that could potentially be misregulated in IPMNs [18-20]. We found that different miRNAs have different expression levels in the patient samples. As shown in Figure 1, some miRNAs (miR-17, miR-107) have very low expression, while on the other hand, miRNAs such as miR-21 have very strong expression levels. These data suggested that we can successfully detect the miRNA expression and different miRNAs are differentially expressed in the IPMN patient samples.

\section{Mis-regulated miRNA expression in IPMN patients}

To further study the potential role of miRNAs in the pathogenesis of IPMNs, we determined the expression of individual miRNAs in IPMN patient samples and the normal control pancreas (NP). As shown in Table 2 and Figure 2, among the 15 miRNAs examined in our study, 9 of them (miR-210, miR-210, miR-223, miR-221, miR-221, miR-221, miR-155, miR-210, miR-223) were significantly differentially expressed between the IPMN samples and the controls. Interestingly, all of those 9 miRNAs were up-regulated in the IPMN patients compared to controls, suggesting that those miRNAs could potentially promote the pathogenesis of IPMNs.

\section{Differential expression of miRNAs in different IPMN subtypes}

We further studied the expression profile of miRNAs in IPMNs, we detected the expression of different miRNAs in different IPMN subtypes. IPMN samples were separated into four different subtypes (G, gastric type; I, intestinal type; $\mathrm{PB}$, biliary pancreatic type; O: oncocytic type). The G and I subtypes of IPMNs have relative good prognosis, while the $\mathrm{PB}$ and $\mathrm{O}$ types of IPMN represent the poor prognosis types. When we compared the miRNA expression levels in different IPMN subtypes, we found that, interestingly, four miRNA (miR-100, miR-187, miR-210, miR-223) levels were up-regulated in the poor prognosis subtypes ( $\mathrm{PB}$ and $\mathrm{O}$ ) compared to the good prognosis subtypes ( $\mathrm{G}$ and $\mathrm{I}$ ) (Table 3 ), suggesting that the expression levels of those miRNAs were associated with the IPMN prognosis statuses.

\section{Differential miRNA expression between chronic pancreatitis (CP), IPMN, and pancreatic ductal adenocarcinoma (PDAC) samples}

The mis-regulated miRNA expression in IPMN suggests the important role of miRNA in IPMN prognosis. Next we studied the expression of miRNAs 
Table 2: Mis-regulated miRNA expression in IPMN patients

\begin{tabular}{|c|c|c|c|c|c|c|c|}
\hline \multirow{3}{*}{$\begin{array}{l}\text { miRNAs } \\
\text { miR-100 }\end{array}$} & \multicolumn{3}{|c|}{ IPMN } & \multicolumn{3}{|c|}{ NP } & \multirow{3}{*}{$\frac{\text { p-value }}{.002}$} \\
\hline & \multirow{2}{*}{$\frac{\text { Mean }}{0.490}$} & \multicolumn{2}{|c|}{ Quartiles } & \multirow{2}{*}{$\frac{\text { Mean }}{0.006}$} & \multicolumn{2}{|c|}{ Quartiles } & \\
\hline & & 0.016 & 3.491 & & 0.004 & 0.010 & \\
\hline miR-107 & 0.298 & 0.024 & 2.757 & 0.004 & 0.002 & 0.013 & .004 \\
\hline miR-452 & 0.045 & 0.002 & 0.582 & 0.001 & 0.000 & 0.002 & .005 \\
\hline miR-21 & 2.539 & 0.236 & 25.642 & 0.159 & 0.079 & 0.334 & .018 \\
\hline miR-221 & 0.162 & 0.017 & 0.871 & 0.002 & 0.000 & 0.007 & .002 \\
\hline miR-155 & 0.807 & 0.178 & 3.812 & 0.024 & 0.018 & 0.051 & .003 \\
\hline miR-187 & 1.315 & 0.192 & 5.399 & 0.002 & 0.001 & 0.006 & .001 \\
\hline miR-210 & 0.220 & 0.137 & 0.600 & 0.002 & 0.001 & 0.004 & .001 \\
\hline miR-223 & 0.739 & 0.202 & 4.178 & 0.002 & 0.001 & 0.005 & .000 \\
\hline
\end{tabular}

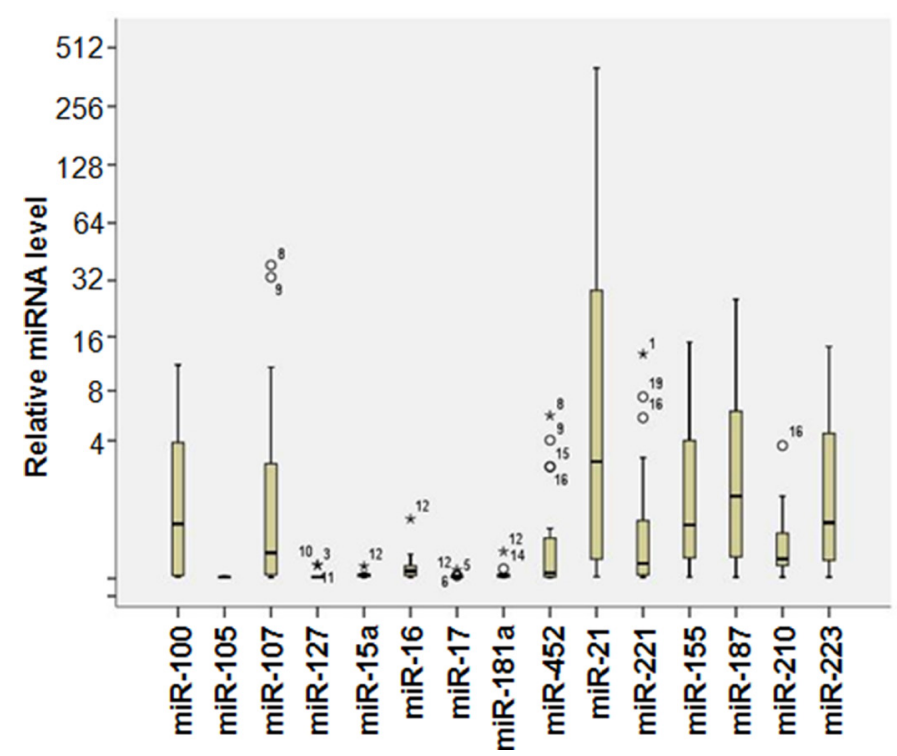

Figure 1: MicroRNA expression profiles in IPMN patient samples. miRNA expression levels were determined by SYBR Green I base quantitative PCR. Briefly, RNA samples were in vitro transcribed in to cDNA using miRNA specific stem-loop RT primers, the the RT products were used for the real time PCR analysis. The expression of individual miRNAs were normalized to Let-7a using $2^{-\Delta \mathrm{Ct}} \mathrm{method}$. $\mathrm{N}=3$.
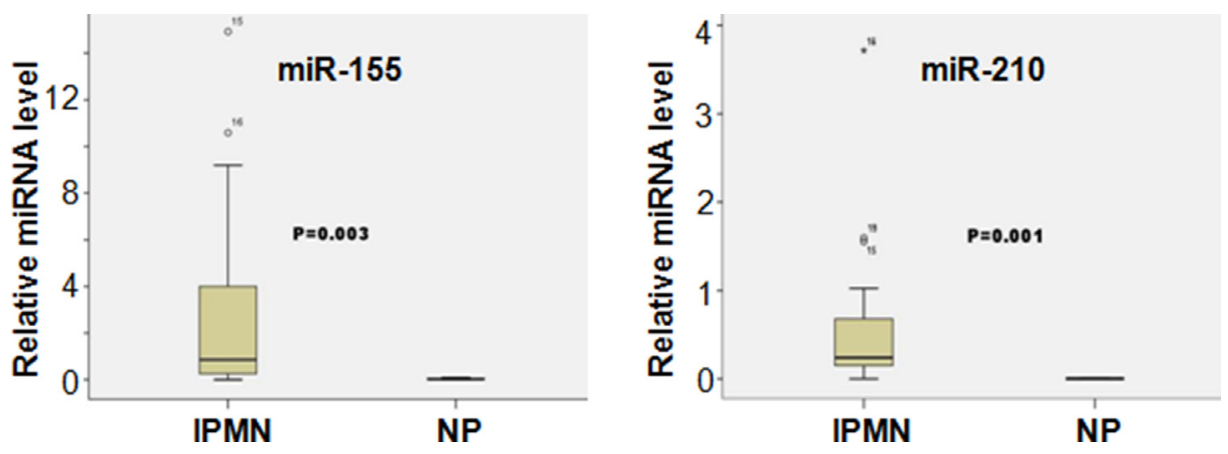

Figure 2: Differential miRNA expression between IPMN and NP samples. The relative expression levels of miR-155 and miR210 were determined by real time PCR analysis using IPMS and NP samples. 
Table 3: Differential expression of miRNAs in different IPMN subtypes

\begin{tabular}{|c|c|c|c|c|c|c|c|}
\hline \multirow{3}{*}{$\begin{array}{c}\text { miRNAs } \\
\text { miR-100 }\end{array}$} & \multicolumn{3}{|c|}{$\mathbf{G}+\mathbf{I}$} & \multicolumn{3}{|c|}{$\mathbf{P B}+\mathbf{O}$} & \multirow{3}{*}{$\begin{array}{r}\text { p-value } \\
0.086\end{array}$} \\
\hline & \multirow{2}{*}{$\frac{\text { Mean }}{0.096}$} & \multicolumn{2}{|c|}{ Quartiles } & \multirow{2}{*}{$\frac{\text { Mean }}{2.281}$} & \multicolumn{2}{|c|}{ Quartiles } & \\
\hline & & 1.384 & 1.939 & & 1.384 & 6.539 & \\
\hline miR-187 & 0.431 & 0.115 & 3.330 & 2.654 & 1.816 & 15.591 & 0.086 \\
\hline miR-210 & 0.194 & 0.110 & 0.304 & 0.678 & 0.318 & 1.288 & 0.037 \\
\hline miR-223 & 0.447 & 0.120 & 2.211 & 3.418 & 0.740 & 6.595 & 0.052 \\
\hline
\end{tabular}

Table 4: Differential miRNA expression between chronic pancreatitis and IPMN patient samples

\begin{tabular}{|c|c|c|c|c|c|c|c|}
\hline \multirow{3}{*}{$\begin{array}{l}\text { miRNAs } \\
\text { miR-21 }\end{array}$} & \multicolumn{3}{|c|}{ IPMN } & \multicolumn{3}{|c|}{$\mathrm{CP}$} & \multirow{3}{*}{$\frac{\text { p-value }}{0.049}$} \\
\hline & \multirow{2}{*}{$\frac{\text { Mean }}{2.539}$} & \multicolumn{2}{|c|}{ Quartiles } & \multirow{2}{*}{$\frac{\text { Mean }}{0.161}$} & \multicolumn{2}{|c|}{ Quartiles } & \\
\hline & & 0.236 & 25.642 & & 0.109 & 1.105 & \\
\hline miR-155 & 0.807 & 0.178 & 3.812 & 0.070 & 0.024 & 0.086 & 0.006 \\
\hline miR-187 & 1.315 & 0.192 & 5.399 & 0.008 & 0.002 & 0.232 & 0.014 \\
\hline miR-210 & 0.220 & 0.137 & 0.600 & 0.010 & 0.002 & 0.038 & 0.003 \\
\hline miR-223 & 0.739 & 0.202 & 4.178 & 0.051 & 0.006 & 0.324 & 0.039 \\
\hline
\end{tabular}

Table 5: Differential miRNA expression between PDAC and IPMN patient samples

\begin{tabular}{|c|c|c|c|c|c|c|c|}
\hline \multirow{3}{*}{$\begin{array}{l}\text { miRNAs } \\
\text { miR-16 }\end{array}$} & \multicolumn{3}{|c|}{ IPMN } & \multicolumn{3}{|c|}{ PDAC } & \multirow{3}{*}{$\begin{array}{r}\text { p-value } \\
0.028\end{array}$} \\
\hline & \multirow{2}{*}{$\frac{\text { Mean }}{0.063}$} & \multicolumn{2}{|c|}{ Quartiles } & \multirow{2}{*}{$\frac{\text { Mean }}{0.157}$} & \multicolumn{2}{|c|}{ Quartiles } & \\
\hline & & 0.011 & 0.140 & & 0.081 & 0.272 & \\
\hline miR-17 & 0.007 & 0.004 & 0.009 & 0.019 & 0.009 & 0.033 & 0.005 \\
\hline miR-181a & 0.021 & 0.001 & 0.030 & 0.073 & 0.018 & 0.182 & 0.008 \\
\hline miR-187 & 1.315 & 0.192 & 5.399 & 0.170 & 0.061 & 0.811 & 0.010 \\
\hline
\end{tabular}

between different pancreatic diseases. The process of carcinogenesis of PDAC is usually considered as a cumulative mutation process that first started with chronic pancreatitis and later tumor development. We first compared the expression of miRNAs between IPMN and CP samples (Table 4), and found that the expression of miR-21, miR-155, miR-187, miR-210 and miR-223 are significantly higher in IPMN patient samples compared to the CP samples. When comparing the IPMN with PDAC samples (Table 5), we identified four different miRNAs, miR-16, miR-17, miR-181a and miR-187, that are differentially expression between the IPMN and PDAC samples. The above differentially expressed miRNAs between CP, IPMN and PDAC samples could serve as novel diagnostic markers for different pancreatic diseases.

\section{DISCUSSION}

MiRNAs are 18 24 nucleotides, non-coding small RNAs that plays important roles in tumorigenesis, development, prognosis, diagnosis and treatment responses. At post-transcriptional level, it binds to the target mRNA, and negatively regulates the expression of the target genes [7]. Recent studies have shown that miRNAs can target important target genes or pathways and play essential roles as oncogenes or tumor suppressor genes in tumorigenesis and progression [21-23], therefore, miRNA could serve as important cancer diagnostic markers and therapeutic targets.

MiRNAs are widely used in the diagnosis of pancreatic cancers. Recent studies revealed that miRNA expressions in pancreatic cancer samples, para-cancerous tissues, normal tissues and chronic pancreatitis were significantly different, suggesting that these differentially expressed miRNAs may be able to detect and treat the pancreatic diseases $[20,24-26]$. Our results revealed that miR-100, miR-107, miR-215, miR-21, miR-221, miR155 , miR-187, miR-210 and miR-223 are differentially expressed between normal pancreas and IPMNs, suggesting that these miRNAs may be specific markers of IPMN. Our profiling data were consistent with some published data reporting the important roles of the above miRNA in pancreatic diseases. For example, miR-155 can inhibit the expression of Tumor protein 53-induced nuclear protein 1 expression and therefore promote pancreatic tumor development [16, 25, 27]. And miR-210 has been identified as a biomarker of pancreatic ductual adenocarcinoma [28]. In addition, the expression of miR21, miR-155, miR-187, miR-210 and miR-223 in are significantly different in IPMN and CP patients and the 
expression of miR-16, miR-181a and miR-187 in were differentially expressed in between IPMNs and PDACs, suggesting that these miRNAs could be used as detection markers for different pancreatic diseases.

Overall, our data suggested that miRNA are important regulators of IPMN and other pancreatic diseases. The differentially expressed miRNAs could potentially be used as novel diagnostic markers and therapeutic targets for the treatment of IPMNs.

\section{MATERIALS AND METHODS}

\section{Patients and clinical samples}

78 cases of IPMN patients treated in Shanghai Changhai Hospital during the period from 2000-2009 were used for this study. The case group consisted of patients with benign IPMN $(n=38)$ and patients with malignant IPMN ( $\mathrm{n}=40)$. Patient samples were tested using different markers including: serum total protein (TP), albumin (Alb), total bilirubin (T-Bil), alanine transferase (ALT), aspartate transferase (AST) and the tumor markers carbohydrate antigen (CA19-9). The postoperative serum levels of ALP, $\gamma$-glutamyltransferase $(\gamma$-GTP), amylase (Amy), carcinoembryonic antigen (CEA). The pathological statuses of the samples were defined with WHO classification criteria. Written informed consents were signed by all the patients before collecting samples. The study protocol was approved by the Institutional Ethic Committee of the Hospital.

\section{Isolation of miRNA from formalin-fixed paraffin-embedded tissues}

MiRNA samples were isolated from Formalin-Fixed Paraffin-Embedded Tissues using the Roche miRNA isolation kit. Briefly, the paraffin specimens were cut into $5 \mu \mathrm{m}$ thick slices and then treated with xylene for 5 minutes at room temperature, then RNA the precipitated using pure ethonal. MiRNA samples were further isolated using the RNA binding column following the manufacturer's instructions.

\section{MiRNA expression analysis}

MiRNA expression was determined using the previously established SYBR Green I based method [29]. The pancreatic paraffin tissue small RNAs were reverse transcribed (RT) into cDNA using different miRNA stem-loop RT primers. Then the RT products were diluted 5 times using $\mathrm{H}_{2} \mathrm{O}$ and used for the Real time PCR analysis. Let-7a was used as internal control. The relative expression levels of miRNAs were calculated using the $2^{-\Delta \mathrm{Ct}}$ method. The presented data were from three independent repeats for each sample.

\section{Statistical analysis}

SPSS 13.0 statistical software was used for statistical processing and statistical charts. Since the miRNA data are non-normally distributed, the expression data are expressed as median and interquartile range. Mann-Whitney $U$ test (two groups) and Kruskal-Wallis $\mathrm{H}$ test (multiple groups) were used for statistical analysis, $\mathrm{p}<0.05$ for the hypothesis test was considered as statistically significant.

\section{Author contributions}

L.W., J.Z., C.S. designed the study, performed the experiment, analyzed the data and wrote the manuscript; L.W, G.J., L.X., Z.J., D.W. performed experiment. Z.L. designed, supervised the study, analyzed data and wrote the manuscript. This work was supported by Grant 81470885 from the National Natural Science Foundation of China.

\section{CONFLICTS OF INTEREST}

The authors declare no conflicts of interest.

\section{REFERENCES}

1. Sohn TA, Yeo CJ, Cameron JL, Hruban RH, Fukushima N, Campbell KA, Lillemoe KD. Intraductal papillary mucinous neoplasms of the pancreas: an updated experience. Ann Surg. 2004; 239:788-97.

2. Del Chiaro M, Verbeke C. Intraductal papillary mucinous neoplasms of the pancreas: reporting clinically relevant features. Histopathology. 2017; 70:850-60. doi: 10.1111/ his. 13131.

3. Nara S, Shimada K, Kosuge T, Kanai Y, Hiraoka N. Minimally invasive intraductal papillary-mucinous carcinoma of the pancreas: clinicopathologic study of 104 intraductal papillary-mucinous neoplasms. Am J Surg Pathol. 2008; 32:243-55. doi: 10.1097/ PAS.0b013e3181484fle.

4. Nara S, Onaya H, Hiraoka N, Shimada K, Sano T, Sakamoto Y, Esaki M, Kosuge T. Preoperative evaluation of invasive and noninvasive intraductal papillary-mucinous neoplasms of the pancreas: clinical, radiological, and pathological analysis of 123 cases. Pancreas. 2009; 38:8-16. doi: 10.1097/MPA.0b013e318181b90d.

5. Lin S, Choe J, Du P, Triboulet R, Gregory RI. The m(6)A methyltransferase METTL3 promotes translation in human cancer cells. Mol Cell. 2016; 62:335-45. doi: 10.1016/j. molcel.2016.03.021.

6. Bracken CP, Scott HS, Goodall GJ. A network-biology perspective of microRNA function and dysfunction in cancer. Nat Rev Genet. 2016; 17:719-32. doi: 10.1038/ nrg.2016.134.

7. Lin S, Gregory RI. MicroRNA biogenesis pathways in cancer. Nat Rev Cancer. 2015; 15:321-33. doi: 10.1038/nrc3932. 
8. Zhu XX, Yan YW, Chen D, Ai CZ, Lu X, Xu SS, Jiang S, Zhong GS, Chen DB, Jiang YZ. Long non-coding RNA HoxA-AS3 interacts with EZH2 to regulate lineage commitment of mesenchymal stem cells. Oncotarget. 2016; 7:63561-70. doi: 10.18632/oncotarget.11538.

9. Davis-Dusenbery BN, Hata A. MicroRNA in cancer: the involvement of aberrant microRNA biogenesis regulatory pathways. Genes Cancer. 2010; 1:1100-14. doi: 10.1177/1947601910396213.

10. Zhang YH, Wang Y, Yusufali AH, Ashby F, Zhang D, Yin ZF, Aslanidi GV, Srivastava A, Ling CQ, Ling C. Cytotoxic genes from traditional Chinese medicine inhibit tumor growth both in vitro and in vivo. J Integr Med. 2014; 12:483-94. doi: 10.1016/S2095-4964(14)60057-1.

11. Wang QZ, Xu W, Habib N, Xu R. Potential uses of microRNA in lung cancer diagnosis, prognosis, and therapy. Curr Cancer Drug Targets. 2009; 9:572-94. doi: 10.2174/156800909788486731.

12. Lin S, Gregory RI. Identification of small molecule inhibitors of Zcchc11 TUTase activity. RNA Biol. 2015; 12:792-800. doi: 10.1080/15476286.2015.1058478.

13. Cheerla N, Gevaert O. MicroRNA based PanCancer diagnosis and treatment recommendation. BMC Bioinformatics. 2017; 18:32. doi: 10.1186/ s12859-016-1421-y.

14. Ji Q, Luo YQ, Wang WH, Liu X, Li Q, Su SB. Research advances in traditional Chinese medicine syndromes in cancer patients. J Integr Med. 2016; 14:12-21. doi: 10.1016/ S2095-4964(16)60237-6.

15. Lubezky N, Loewenstein S, Ben-Haim M, Brazowski E, Marmor S, Pasmanik-Chor M, Oron-Karni V, Rechavi G, Klausner JM, Lahat G. MicroRNA expression signatures in intraductal papillary mucinous neoplasm of the pancreas. Surgery. 2013; 153:663-72. doi: 10.1016/j. surg.2012.11.016.

16. Caponi S, Funel N, Frampton AE, Mosca F, Santarpia L, Van der Velde AG, Jiao LR, De Lio N, Falcone A, Kazemier G, Meijer GA, Verheul HM, Vasile E, et al. The good, the bad and the ugly: a tale of miR-101, miR-21 and miR-155 in pancreatic intraductal papillary mucinous neoplasms. Ann Oncol. 2013; 24:734-41. doi: 10.1093/annonc/mds513.

17. Efe C. Role of serum carbohydrate antigen 19-9 and carcinoembryonic antigen in distinguishing between benign and invasive intraductal papillary mucinous neoplasm of the pancreas. Br J Surg. 2011; 98:104-10. doi: 10.1002/ bjs. 7280 .

18. Bloomston M, Frankel WL, Petrocca F, Volinia S, Alder H, Hagan JP, Liu CG, Bhatt D, Taccioli C, Croce CM. MicroRNA expression patterns to differentiate pancreatic adenocarcinoma from normal pancreas and chronic pancreatitis. JAMA. 2007; 297:1901-8. doi: 10.1001/ jama.297.17.1901.

19. Szafranska AE, Doleshal M, Edmunds HS, Gordon S, Luttges J, Munding JB, Barth RJ Jr, Gutmann EJ, Suriawinata AA, Marc Pipas J, Tannapfel A, Korc M,
Hahn SA, et al. Analysis of microRNAs in pancreatic fine-needle aspirates can classify benign and malignant tissues. Clin Chem. 2008; 54:1716-24. doi: 10.1373/ clinchem.2008.109603.

20. Szafranska AE, Davison TS, John J, Cannon T, Sipos B, Maghnouj A, Labourier E, Hahn SA. MicroRNA expression alterations are linked to tumorigenesis and non-neoplastic processes in pancreatic ductal adenocarcinoma. Oncogene. 2007; 26:4442-52. doi: 10.1038/sj.onc.1210228.

21. Peng L, Hu Y, Chen D, Jiao S, Sun S. Ubiquitin specific peptidase 21 regulates interleukin- 8 expression, stem-cell like property of human renal cell carcinoma. Oncotarget. 2016; 7:42007-16. doi: 10.18632/oncotarget.9751.

22. Liang P, Song Z, Chen D, Linghu R, Wang Y, Zhang X, Kou $\mathrm{X}$, Yang J, Jiao S. GINS2 regulates matrix metallopeptidase 9 expression and cancer stem cell property in human triple negative breast cancer. Biomed Pharmacother. 2016; 84:1568-74. doi: 10.1016/j.biopha.2016.10.032.

23. Liang Y, Zhu F, Zhang H, Chen D, Zhang X, Gao Q, Li Y. Conditional ablation of TGF-beta signaling inhibits tumor progression and invasion in an induced mouse bladder cancer model. Sci Rep. 2016; 6:29479. doi: 10.1038/ srep29479.

24. Lee EJ, Gusev Y, Jiang J, Nuovo GJ, Lerner MR, Frankel WL, Morgan DL, Postier RG, Brackett DJ, Schmittgen TD. Expression profiling identifies microRNA signature in pancreatic cancer. Int J Cancer. 2007; 120:1046-54. doi: 10.1002/ijc. 22394.

25. du Rieu MC, Torrisani J, Selves J, Al Saati T, Souque A, Dufresne M, Tsongalis GJ, Suriawinata AA, Carrere N, Buscail L, Cordelier P. MicroRNA-21 is induced early in pancreatic ductal adenocarcinoma precursor lesions. Clin Chem. 2010; 56:603-12. doi: 10.1373/ clinchem.2009.137364.

26. Gironella M, Seux M, Xie MJ, Cano C, Tomasini R, Gommeaux J, Garcia S, Nowak J, Yeung ML, Jeang KT, Chaix A, Fazli L, Motoo Y. Tumor protein 53-induced nuclear protein 1 expression is repressed by miR-155, and its restoration inhibits pancreatic tumor development. Proc Natl Acad Sci U S A. 2007; 104:16170-5. doi: 10.1073/ pnas.0703942104.

27. Habbe N, Koorstra JB, Mendell JT, Offerhaus GJ, Ryu JK, Feldmann G, Mullendore ME, Goggins MG, Hong SM, Maitra A. MicroRNA miR-155 is a biomarker of early pancreatic neoplasia. Cancer Biol Ther. 2009; 8:340-6. doi: 10.4161/cbt.8.4.7338.

28. Wang J, Chen J, Chang P, LeBlanc A, Li D, Abbruzzesse JL, Frazier ML, Killary AM, Sen S. MicroRNAs in plasma of pancreatic ductal adenocarcinoma patients as novel bloodbased biomarkers of disease. Cancer Prev Res (Phila). 2009; 2:807-13. doi: 10.1158/1940-6207.CAPR-09-0094.

29. Tang F, Hajkova P, Barton SC, Lao K, Surani MA. MicroRNA expression profiling of single whole embryonic stem cells. Nucleic Acids Res. 2006; 34:e9. doi: 10.1093/ nar/gnj009. 